\title{
Research on the Fusion Mechanism and Formation Pathway of Compound-type Postgraduate Talents Cultivation System
}

\author{
Chaotian Chen* \\ School of Computer Science \\ Guangdong Polytechnic Normal University \\ Guangzhou, P.R. China \\ chencht@tom.com
}

\author{
Hui Li \\ School of Computer Science \\ Guangdong Polytechnic Normal University \\ Guangzhou P.R. China \\ 563927941@qq.com
}

\author{
Shaozhi Ji \\ School of Computer Science \\ Guangdong Polytechnic Normal University \\ Guangzhou P.R. China \\ 563927941@qq.com
}

Abstract-The cultivation problems of compound-type postgraduate talents is studied from the perspective of mechanism fusion. The cultivation of compound-type postgraduate is seen as a system, and the theories and research methods of system science, pedagogy, psychology, management science are applied to study the generative foundation, fusion principle, and formation pathway of cultivation mechanism. Firstly, from the perspective of methodology, the generative foundation of the fusion mechanism of compound-type postgraduate talents cultivation are revealed, which is related to technology and social progress, single-subject cultivation object, human cognitive level, the dynamics of cultivating talent, etc. Secondly, the fusion principle is presented by using the system theory, such as object orientation, structure coordination, and overall optimization, adapt environment and dynamic development, etc. Finally, from the views of overall optimization, the formation pathway is proposed such as disciplines, policies, ideas, demands and projects. By applying the system thinking, this article provides a new theoretical foundation and fusion method for cultivating compound-type postgraduate talents.

Keywords-compound-type; postgraduate; cultivation system; mechanism; fusion

Under the new social background of economic globalization, information networking and cultural pluralism, the cultivation of compound-type postgraduate talents is becoming more and more important, and it is an important subject of education how to improve the quality of the culture from the cultivation mechanism. Different scholars and organizations are discussing different cultivation mechanisms, which raises the questions of whether these mechanisms can be fused and how to fuse. In this paper, the cultivation of compound-type postgraduate is regarded as a system which applying the theories and methods of system science to study the generative foundation, fusion principle, and formation pathway of cultivation mechanism.

This paper is supported by the project of Guangdong Graduate Education Innovation Program (sfkc2014-28, system science).

\section{GENERATIVE FOUNDATION OF TALENT CULTIVATION MECHANISM FOR COMPOUND-TYPE POSTGRADUATE}

A. The Anastomotic of the Objectivity of Postgraduate Education Development with the Reality of Science Technology and Social Progress

The annual enrollment scale of full-time postgraduate education in China has exceeded 630,000 in 2015, more than double the enrollment scale of college entrance examination in the late 1970s. The rapid expansion of postgraduate enrollment have made the postgraduate education gradually tend to be popular; and the rapid expansion of the enrollment scale of college entrance examination makes the teaching resources for postgraduates tense and the teaching quality uneven. The specialty setting for postgraduates is too limited and the application of employment is too less, resulting in that the employment of postgraduates from some schools and some specialties tends to be difficult [1]. In the mode of traditional and single postgraduate education, some traditional disciplines even with the knowledge acquired by the professional postgraduate student may also "vary dramatically from different lecturer".

However, facing with the challenge of new technology revolution in the present, the modern science has gradually tended to dominate in the comprehensive development; a large number of interdisciplinary disciplines and inter-disciplines have emerged, the science and technology have been increasingly integrated; any discipline have to rely on some knowledge and methods of other disciplines for development [2]. For example, the lawyers shall be proficient in laws and have considerable knowledge of Economics, including knowledge of foreign trade and Finance, as well as the knowledge of sociology and psychology, thus all kinds of cases can be handled well. According to statistics, the ratio of the newly generated differentiated disciplines to the newly 
generated interdisciplinary disciplines is about 1:4. Under the background of economic globalization, information network and cultural pluralism, a large number of professional and technical talent and management talents with compound-type knowledge and compound-type abilities are needed urgently in the society with the progress of science, technology and society.

The traditional single postgraduate cultivation system has trained millions of postgraduates for the economic development of our country, but if it continues to utilize this cultivation mode in a single way, this will lead to the oversupply of postgraduates in some disciplines or fields, while other disciplines and fields that meet the demands of the new era are in short supply; and thus the division of popular and unpopular specialties of the times will morbidly circulate. In this way, it is not suitable for the urgent needs of social development and is not conducive to the coordinated development of various disciplines, but also does not meet the practical needs of postgraduate education development. Therefore, the traditional single postgraduate cultivation mode has been unable to meet the requirements of the postgraduate education development and technological, social progress, and the birth of new cultivation model is urgently appealed. The demand of reality exactly gives birth to the compound-type postgraduate talents cultivation mode; it not only conforms to the growth law and fusion foundation of today's postgraduate cultivation, but also can make up for the shortage of traditional postgraduate cultivation mode and breaks through the bottleneck of postgraduate development in China.

\section{B. The Internal Consistency and Compatibility of the}

Cultivation Objective of Compound-type postgraduate and Single-specialist-type Postgraduate

The goal of cultivation is the embodiment of direction and specification of talent cultivation by combining the educational thoughts and certain conditions for running school. Compoundtype postgraduate talents cultivation system is aimed at fusing and integrating the professional knowledge of related disciplines and cultivating the new type of postgraduate student who have complex knowledge structure, comprehensive thinking structure and pioneering creative ability and can quickly adapt to the development of society, science and technology. While the goal of the single-specialist-type postgraduate talent cultivation system is based on discipline differentiation; it only relies on the knowledge of a discipline to cultivate the single-specialist-type talents who are proficient in one professional knowledge but lack of knowledge in other areas. The former is usually reflected in the intersection of disciplines, and the latter is reflected in the singleness of disciplines.

It should be said that both the postgraduates of compoundtype and single-specialist-type both support national economic construction, they are the driving force of the development of science and technology; they conform to the needs of the development of the times [3]. Compound-type postgraduate students and single-specialist-type postgraduates are talents with the general characteristics of talents, i.e. the moral, intellectual and physical aspects are developed accordingly; they master certain knowledge, ability and methods and can be competent for certain creative works, etc. Therefore, the cultivation objectives of the two modes are consistent in basic requirements and easy to be transplanted and fused.

Single-specialist-type talents generally belong to the single discipline talents, which the compound-type talents need multidisciplinary knowledge. Single-specialist knowledge is the foundation of compound-type knowledge, and solid single knowledge is helpful for understanding other disciplines and transplantation of methods. The traditional single-specialisttype postgraduates may turn into the compound-type talents after learning the second and third specialty. But compoundtype postgraduates are also possible to become the single talents if they stick to a corner in the future work or self-close and remain stagnant. Therefore, a lot of knowledge, methods and capabilities of both parties are compatible, and the cultivation objective is also compatible. It is feasible to extend to the cultivation of compound-type postgraduate talents since our country has accumulated mature experiences in the cultivation of single-specialist-type talents.

\section{The Adaptability about Ability of Compound-type \\ Postgraduate and Development Requirements of Human Cognitive Level}

The cognitive level of human beings is constantly developed from single dimension to multi-dimension. Observing the same thing from different angles will have different understandings; and it should take into account its multidimensional nature for the formation of complete understanding of things. " Walk around the hill and recognize the view vary when you look at them from the different angle" and "cannot see through what the Mountain Lu really looks like, only because you are on the Mountain" said by Su Shi are exactly the good examples. Only those talents with compoundtype knowledge structure can do this [4]

The development of human cognitive level depends on the knowledge acquired by human beings themselves. With the progress of science and technology, numerous new technologies and new techniques continue to emerge, followed by the increasingly accelerated updating of knowledge. According to relevant research, the knowledge updates about every five years, and there should be 8 renewal opportunities if the effective working life of the individual is 40 years. Otherwise, people cannot keep up with the development of society. Therefore, the compound-type postgraduate talents can adapt to the requirement of the development of human cognitive level.

Cognitive Psychology regards cognitive process as a process of information processing; it considers the cognitive process of attention, feeling, perception, memory, imagination, thinking and language is the process that the brain receives information from the outside, and processes through the brain and transforms into the internal psychological activity, and then controls the human behavior.

Such as memory, which needs the process of processing, storage, extraction and change. People's cognitive level is a process of continuous development; the compound-type knowledge and consciousness also need a gradually improved process. 


\section{The Coexistence of Dynamic Development and Balance for} Cultivation of Compound-type Postgraduate

The compound-type postgraduate talents cultivation system is a dynamic system. It constantly adjusts itself with the progress of the times, social progress, knowledge update, technological upgrading, it exports information to external environment and discharges old things. At the same time, it absorbs new things from external environment, which is a metabolic cultivation system.

The compound-type postgraduate talents cultivation system develops to a certain equilibrium state; it is relatively static when the system reaches this equilibrium state; and when the external environment changes, this system enters a new round and develops towards a new equilibrium state. "Developmentbalance-development", the system repeats constantly.

It can be seen that the cultivation process for compoundtype postgraduate students is the process of continuous improvement and gradual adaptation to the needs of social development, sequential following of the knowledge and the pace of technological development [5]. When the balance is reached, the postgraduates promote the progress of society, knowledge and technology; and the progress of the three aspects raises a new level for the cultivation of postgraduates. It circulates and repeated like this, but this repetition is not simply from the starting point back to the starting point, but rising spirally, which is higher level than the original ones.

\section{E. The Complementarity of Compound-type Postgraduate and Single-specialist-type Postgraduate Cultivation}

The trend of modern science and technology from high differentiation to totalized and integrated development as well as the intercross and penetration of various subjects have formed a series of new disciplines, and thus a large number of compound-type postgraduates with consummate professional knowledge and extensive basic knowledge and other subject knowledge are required.

There are some disadvantages in the single-specialist-type postgraduate cultivation system, such as relatively simply and lagging. But after all, it is decided by the objective needs of our national economic development for high-level and specialized talents, and it also has made great contributions in the highly differentiated period of discipline technology, which is very mature [6]. Its rich experience accumulated can provide reference for the new talent cultivation system of compoundtype postgraduate students and leads less detours for the implementation process.

On the contrary, it does not totally deny the reform of single-specialist-type of postgraduate cultivation system but develops what is useful or healthy and discards and what is not, retains its essence, absorbs the strengths of the new system and optimizes it [7].

Therefore, compound-type postgraduate cultivation should not cause impact on the postgraduate to the single-specialisttype postgraduate talent cultivation, it's just a necessary and timely supplement. The single-specialist-type postgraduate talent has mastered the solid and broad basic theory as well as systematic and deep professional knowledge, and they can master the professional knowledge of the second subjects on this basis. The knowledge of two subjects and the mutual complementation ways of thinking can help to grasp the pulse of the times and understand the new progress of the international front so as to bring forth the new, thus they can also be compound-type talents.

\section{THE FUSION PRINCIPLE OF TALENT CULTIVATION} MECHANISM OF COMPOUND-TYPE POSTGRADUATE STUDENTS

\section{A. Object Location Principle}

Target orientation of cultivating postgraduates in schools is the key point, and the reform of compound-type development, curriculum system construction and teaching methods can be carried out according to the cultivation objectives only with definite cultivation target. In order to correctly position the cultivation target of compound-type postgraduate students talents, the realistic environment and conditions required by them shall be analyzed, and their professional judgment consciousness and ability shall be strengthened through the reform of curriculum setting, the improvement of teachers' composite quality, the reform of teaching methods and the establishment of practical teaching system, etc. so as to train the compound-type practical talents who can adapt to the complex and changeable economic environment and meet the needs of the society [8].

Therefore, colleges and universities should fully coordinate to the advantages of the applied disciplines through correctly positioning the cultivation objectives of compound-type postgraduate students in the process of performing their functions; and it shall realize the system with cross-hierarchy, portability and high comprehensiveness to integrate into a compound-type postgraduate talents cultivation mechanism through the transcendence of the traditional cultivation mechanism and technological upgrading [9]

\section{B. Structural Coordination Principle}

The structure is a common property of system; the postgraduate talent cultivation system is a complex system, and there are a lot of elements inside; these elements maintain orderly and coordinated structure in a certain era environment, and they often maintain a certain degree of activity to the environment, so that the system must continue to exchange substance and information in order to maintain a stable system structure. The specialized education for a long time and the various elements of postgraduate cultivation system may serve for professional education, or it is the product of professional education. In modern times, the structure of postgraduate cultivation system is not in a stable state any more, it is necessary to coordinate the interconnection and interaction between the elements, so that they can recover the stable state [10].

Therefore, all the coordination of management policy, discipline layout, the professional knot setting, the teacher troop and the curriculum system just lay the foundation for the formation of compound-type postgraduate cultivation mechanism in the reform of postgraduate education in China [11]. 


\section{Overall Optimization Principle}

The whole system can produce the new effect that each component does not have, since the intercommunication and interaction form a synergistic reaction among the components of the system; only through the synergy can the overall effect of the system can be manifested. The cultivation system for postgraduates' talents in our country should not attach importance to the effect of a certain cultivation system but investigate the integrity of system. Single-specialist-type postgraduate cultivation system doesn't adapt to the development of the times, and great efforts should be made to coordinate and develop other postgraduate student cultivation systems for producing the overall effects.

Therefore, it shall coordinate the functions of each subsystem from the whole of postgraduate cultivation system according to the definite cultivation target for postgraduate student to make their respective functions produce amplification effect and give full play to the overall optimization effect of postgraduate cultivation system while promoting the formation of compound-type postgraduate talents cultivation mechanism.

\section{Adapt Environment Principle}

The postgraduate talent cultivation system is produced in a certain environment, and operates, continues and evolves in this environment. The structure, state and attribute of cultivation system are related to the environment. It depends on the environment, and the environment objectively exists; it needs to adapt to the environment. Environment refers to the general term of things that exist outside the system, it is a more advanced and complicated system; its change has a great influence on the system, and the system must adapt to the changes in the external environment, the ideal system is the system that can maintain the best state of fit with the external environment.

Obviously, the external environments such as the rapid development of social economy and culture, the short update cycle of knowledge technology and the contradiction between supply and demand of composite posts require the development of compound-type postgraduate cultivation mechanism; and the comprehensive improvement of university, the diversity of subjects, the compound-type cultural atmosphere and the selfdemands of postgraduates promote the fusion of the cultivation mechanism of the compound-type postgraduate talents [12].

\section{E. Dynamic Development Principle}

The openness and environmental adaptability of postgraduate cultivation determine the postgraduate cultivation system as a dynamically developed system. Its development direction, speed, degree, characteristics and style are determined by the changes of external environment and internal environment. Thus, we can judge which postgraduate cultivation subsystem is more effective and more suitable for the development of the times, and which postgraduate cultivation subsystem should be supported.

In short, the external environment now urgently requires the compound-type postgraduate students' talents to be input by the postgraduate system, and this system will focus on developing the subsystem of the compound-type postgraduate students' talents [13]. In the meantime, the structure of each subsystem of postgraduate cultivation system changes, breaks the stable state and adjust the proportion of subsystems. All these can effectively speed up the formation of the compoundtype postgraduate cultivation system.

\section{THE FORMATION PATHWAY OF TALENT CULTIVATION} MECHANISM OF COMPOUND-TYPE POSTGRADUATE STUDENTS

\section{A. The Discipline-oriented and Natural Fusion Path}

Modern disciplines, both natural and social disciplines, show a highly integrated trend; and interdisciplinary disciplines, cross disciplines and traverse disciplines emerge. These disciplines lead the emergence, formation and development of compound-type postgraduate talents, lead the whole cultivation system and promote the overall development of the cultivation system to play a leading role. They freely cross and fuse without the outside disturbance according to the development and change of law of discipline system.

In the last 25 years, the proportion of cross research has risen to $47 \%$ in the Nobel prizes. People are faced with a lot of highly-integrated and complex problems that cannot be solved by a single discipline, such as environment, population, resources and other issues; they all require the social disciplines and natural discipline to be integrated and cooperated, thus the problems can be solved [14].

Therefore, the dominant position of discipline in postgraduate cultivation system and the natural fusion of all disciplines not only produce the new compound-type disciplines, but also form the compound-type postgraduate cultivation mechanism that cultivates, learns and researches these disciplines.

\section{B. The Administrative Decision and Decision-led Path}

The administrative departments of colleges and universities systematically analyze the subjective and objective conditions, and formulate the policies that are conducive to the cultivation of compound-type postgraduate students by applying scientific theories and methods according to the social demands for talents and their own conditions for running schools in order to achieve the intended purpose of cultivating the postgraduates, and thus the compound-type postgraduate cultivation mechanism forms [15].

The educational administration departments have realized the harmfulness of the unreasonable structure of disciplines, and they require the universities to pay attention to the improvement of the subject structure. Lack of the policy directly affects the whole process of the cultivation of compound-type postgraduate students; and there is no suitable discipline setting and no suitable cultivation program published.

It shall formulate special policies to encourage students to register for examination cross the discipline and major; and it should give certain inclination and support in the admission policy for postgraduates [16]. With some comprehensive universities as the pilots, it shall set up the compound-type discipline specialty and increase the conferring right for the compound-type doctorate and master. It is conducive to the improvement of the guidance level of postgraduate tutors, helps the postgraduates seize the forefront in the high academic 
commanding heights, and facilitates the formation of a compound-type postgraduate cultivation mechanism.

\section{The School Running Ideas and Thought-influenced Path}

The School Running Thought is the embodiment of the educational policy, the reflection of the running of colleges and universities, and the foundation of setting up a school. The School Running Idea is the soul of colleges and universities, and it shall strive to perfect this idea in practice.

It is the ideological basis and forerunner of postgraduate teaching reform practice to change the School Running Thought, and this is also the prerequisite for implementing the research education and cultivating the compound-type postgraduates. The comprehensive, systematic and deep School Running Idea of universities reflects that the compound-type postgraduate education is a practical activity involving many factors, such as science, technology, society, economy, thinking, traditional habits, etc.

In the process of cultivation, the university administrators and teachers should break the School Running Thought of traditional single discipline for cultivating the postgraduates, and they shall establish the consciousness and strategic vision of compound-type infiltration, and recognize the dialectical relationship between single discipline cultivation and compound-type cultivation to vigorously promote the philosophy influence of compound-type postgraduate education.

\section{The Social Development and Demand-promoted Path}

The social development and market demand is the external environment of the compound-type postgraduate talents cultivation system, which affects the emergence and development of the system; in turn, this system should adapt to the social development and market demand [17]. Cultivating compound-type postgraduate talents is the need of the Socialist Modernization Drive in China. The problems of population, economy, resources and environment faced by the social development are the complex problems involving multiple factors, levels, and subjects; only by relying on the relevant subjects of natural subjects, technology science, social science and humanities science accompanied by the efforts to fight in coordination can these problems be solved. Compound-type postgraduate talents are higher-level workers, and the quantity, level and requirements of specialty structure are determined by many factors, but ultimately it is determined by the scale, level and structure of social development [18].

Therefore, only those compound-type talents who have strong basic scientific theory, multi-disciplinary expertise, various technologies and higher humanity, social sciences literacy can solve the problems faced by social development. Social development and market demand promote the formation of compound-type postgraduate talents cultivation mechanism [19].

\section{E. The Feedback and Suggestion-integrated Path}

The feedback and suggestion integration are the bridge of information exchange between the compound-type postgraduate talents cultivation system with the external environment, which has the feedback control effect on the development of this system, reduces the deviation between the actual development process and the expected target, and constantly optimizes and perfects the system.

In the testing stage of the compound-type postgraduate talents cultivation mode, the feedback and suggestion integration from all sides are particularly important, which also provide guidance for the development of this mode. For cultivating compound-type postgraduate talents, the state need is the premise and the social demand is the orientation. The feedback and suggestions put forward by the nation and employers include the requirements for the ability and knowledge of the compound-type postgraduate talents as well as the changing trend of postgraduate talents needed in today's society. It is beneficial for the compound-type postgraduate talents to better understand the reality and shorten the growth time after the post; and it is conductive for the employing units to select suitable compound-type postgraduate talents.

The traditional closed cultivation should be abandoned in the cultivation process for compound-type postgraduate students, and it shall advocate the open cultivation and strengthen the horizontal linkages between different schools, schools and local enterprises, units and departments; and the feedback and the integrated suggestion can provide valuable experiences for the cultivation of compound-type postgraduate students [20]. It should give full consideration to the feedback and suggestions of employers and other schools in the process of formulating the Compound-type postgraduate talents cultivation mechanism.

\section{F. The Project Match in Coordination with the Experience Path}

It shall adhere to regard the theme as the core to affect the operation of learning and research of compound-type specialty (discipline); and it also should cooperate with the tutors to experience the compound-type knowledge, compound-type research methods and compound-type thinking contained in the themes.

The project match and collaborative experience shall be persevered in. First of all, the subject study leads the postgraduates of different disciplines to selectively supplement the lacked knowledge of related disciplines autonomously and construct a complete knowledge structure [21]. Secondly, students from different disciplines communicate with each other, and knowledge is intersected and permeated here. Thirdly, it leads the students to think deeply about the compound-type knowledge, and the knowledge is internalized and fused. Finally, the students learn the knowledge of related subjects in a specific way, consult the relevant books and documents actively, practice the knowledge leaned constantly and enhance the manipulative ability; and they are familiar with certain academic research methods, which lays the foundation for the composition of thesis in the future. It combines the teaching with research to form the overall matrix of talent cultivation and pull the formation of talent cultivation mechanism for compound-type postgraduate talents. 


\section{CONCLUSION}

The system methodology is used to reveal the generative foundation of the fusion mechanism for compound-type postgraduate talents cultivation, and provides a new theoretical basis for the fusion mechanism. By using the principles of systematics, the principles are put forward which must be followed in the process of fusion, and are the guiding ideology in the process of integration. The optimization approach proposed from the integrity of the system provides a fusion method for the cultivation mechanism. In the meanwhile, the universality of application of system thinking is revealed in this paper.

\section{REFERENCES}

[1] Wang Zheng-qing and Gu Hong-chen, "Explore to Construction the Environment of Cultivating Allround Graduate Students," Academic Degrees and Graduate Education, vol. 4, pp.11-13, July 1998 (4). (In Chinese)

[2] Tight, M. Researching Higher Education. London and Bucking: SRHE and Open University Press, 2003, pp.110-125.

[3] Zhu Yan, "Reform of Talent Cultivation Mode from the Interdisciplinary Talent Cultivation in Colleges and Universities," Continue Education Research, vol. 2, pp. 97-98, December 2009. (In Chinese)

[4] Zhang Xinchang and Zhong Shanshan, "Discussion on 'EnterpriseAcademics-Research’ Co-cultivation for Interdisciplinary Postgraduate mode," Studies in Higher Education, vol. 1,pp. 57-60, January 2009. (In Chinese)

[5] Osmo Kivinen, Sakari Ahola,Paivi Kaipainen(Eds), Towards the European Model of Postgraduate Training, University of Turku, RUSE Report50, January 1999.2,3,139.

[6] Lu Bing, “Adapting to the Needs of Social Development and Focusing on the Cultivation of Interdisciplinary Postgraduate,” Journal of Nanjing University of Chemical Technology, vol. 1, pp. 88-90, July 2005. (In Chinese)

[7] Zhao Pengda. "Strengthen Graduate Education Reform to Promote Cultivating Multidisciplinary Compound Talents,” Academic Degrees and Graduate Education, vol. 5, pp. 12-14, September 1996. (In Chinese)

[8] Zhang Rencai, "Cultivating Compound Talent to Adapt to Sustained Economic Development,” Chinese Vocational and Technical Education, vol. 4, pp. 50-51, April 1994. (In Chinese)
[9] Qi Fengwei, Wang Shaoyuan, Liu Guorui, Liu Guirong and Li Guojie, "Meeting the Challenge of Twenty-first Century-Modes and Countermeasures of Cultivating Interdisciplinary Talents in College and Universities,” Jilin Education Science, vol. 11, pp. 12-17, November 1997. (In Chinese)

[10] Barbara and Jacoby, Service - learning in Higher Education: Concepts and Practices, Jossey-Bass Publishers. San Francisco, pp. 245-249, 1996

[11] Sun Ping and Zhu Guilong, "Discussion on Interdisciplinary Education of College,” Journal of Hefei University of Techno log, vol. 4, pp. 102104, December 2000. (In Chinese)

[12] Li Xingye, "Exploration on Interdisciplinary Education and Talent Cultivation in the Higher Education Institutions of US,UK, France and Japan,” Modern University Education, vol. 5, pp. 71-75, October 2004. (In Chinese)

[13] Xu Mailin and Ye Lin, "Graduate Education in the 21st Century --- The New Movements and Trends of the Graduate Education in the World," Journal of Zhejiang University, vol. 3, pp. 155-160, June 2001. (In Chinese)

[14] Pang Qingshan and Xie Anbang, "Comparative Research of Development Roade on Graduate Education with German and American,” Comparative Education Research, vol. 10, pp. 18-22, October 2002. (In Chinese)

[15] Yuan Ruie and Hu Anna, "Current Trends of Postgraduate Education Development in USA and UK,” Comparative. Education Review, vol. 9, pp. 41-45, September 2003. (In Chinese)

[16] Liu Zhou, Gu Yao and Ma Lili, “Analysis of Countermeasures for Strengthen Interdisciplinary Graduate Education--- Enlightenment of Interdisciplinary Education on America, English and France,” Higher Education of Sciences, vol. 6, pp. 56-60, December 2006. (In Chinese)

[17] Robin Humphrey and Peter McCarthy, "Recognizing Difference: Providing for Postgraduate Students,” Studies in Higher Education, vol. 3,pp.371- 378, 1999.

[18] Svein Kyvik and Olaf Tvede, "The Doctorate in the Nordic Countries," Comparative Education, vol. 1, pp. 9-15, 1998.

[19] Zhan Lijuan and Xu Qingshan, "Present Situation and Approaches on Interdisciplinary Cultivating Graduate Students ," China Electric Power Education, vol. 19, pp. 58-60, July 2010. (In Chinese)

[20] Luo Shijian, Chen Hangyu and Sun Shouqian, "Research on the Approaches of the All-round Graduate Education,” Heilongjiang Researches on Higher Education, vol. 6, pp. 76-77, November 2006. (In Chinese)

[21] Jones P and Merritt Q, "Critical Thinking and Interdisciplinary in Environmental Higher Education,” Geography in Higher Education, vol. 3, pp. 349-357, August 1999. 